\title{
Book review \\ Physicochemical Principles of Pharmacy: In Manufacture, Formulation and Clinical Use. 6th ed.
}

\section{Beverley Glass}

Professor of Pharmacy

College of Medicine and

Dentistry

James Cook University

Townsville

Queensland

Aust Prescr 2016:39:178

http://dx.doi.org/10.18773/ austprescr.2016.065

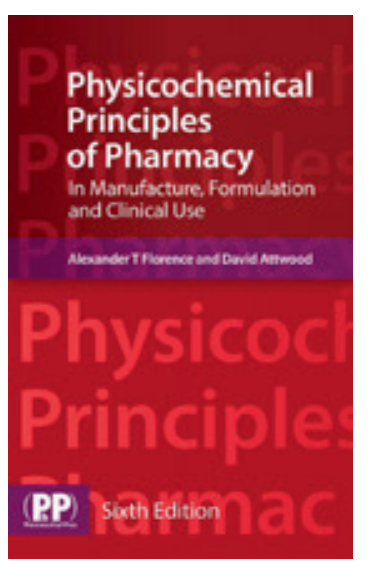

Florence AT, Attwood D

London: Pharmaceutical Press; 2016.

\section{7 pages}

This new edition of an established textbook continues to provide comprehensive coverage of physicochemical principles in relation to drug properties, dosage form design, and delivery by various routes to sites of action in the body. As the title indicates, aspects of manufacture, formulation and clinical use have been added to this edition.

The text is highly illustrated throughout and includes key points and appropriate examples, providing clinicians with some easily accessible and relevant information. The clinical points and case studies are of particular use in the chapters on paediatric and geriatric formulations and adverse events.

Greater need for the personalisation of medicines has placed emphasis on the flexibility of dosage forms to deliver tailored dosages. While not a comprehensive guide, the chapter providing insight into dose formulations at different ends of the age spectrum is very useful.
In the chapter on adverse events, the role of formulation and delivery systems highlights the often incorrect assumption that adverse events can only be attributed to the drug. Some examples of adverse events due to excipients, impurities, the influence of dosage forms, materials in delivery devices and even light-induced effects are also included. Although the detection of adverse events is not an easy task, these examples may assist clinicians in asking the right questions to predict or identify adverse effects.

The final chapter contrasts generic medicines with biosimilars. It discusses why biosimilars (macromolecular or protein-based drugs) are often not able to be classified as identical to the brand leader, but 'similar' and not 'equivalent'.

The new focus on applications to clinical practice in this edition has extended its usefulness from pharmacy and pharmaceutical scientist courses to clinicians seeking an understanding of formulations, especially for children and older people, and in identifying the cause of adverse events. 